\title{
Plant parasitic nematodes fauna in citrus orchards in Khuzestan province, Southwestern Iran
}

\author{
P. Eisvand ${ }^{1}$, R. Farrokhi Nejad' ${ }^{1}$ and S. Azimi ${ }^{1 *}$
}

Summary During a survey on the biodiversity of plant-parasitic nematodes in citrus orchards of Khuzestan province (Southwestern Iran), 97 root and soil samples were collected. Nematodes were extracted and identified using morphological and morphometric diagnostic characters. Six nematode species were identified, namely: Helicotylenchus abunaamai, H. crenacauda, Pratylenchus allius, P. musii, Psilenchus hilarulus and Tylenchulus semipenetrans. Except T. semipenetrans, the remaining five species were found only in the rhizosphere of citrus, not in citrus roots, and their pathogenicity on citrus plants was not further studied. This is the first record of $P$. allius and $P$. musii for the nematode fauna in Iran. $H$. crenacauda is a new record for the nematode fauna in the Khuzestan province and is reported for the first time in citrus orchards in Iran. To our knowledge, this is the first report of H. abunaamai in citrus orchards worldwide.

Additional keywords: citrus, first record, morphology, morphometric, plant-parasitic

\section{Introduction}

Citrus is indigenous to southeastern Asia but has existed in Mediterranean basin for centuries. Species of citrus have great importance in some Mediterranean regions (Duarte et al., 2016). Iran is the eighth largest producer of citrus in the world. In 2017, Iranian citrus fruit production reached 4,067,000 tons (FAOSTAT, 2017). Khuzestan province is one of the major citrus-producing regions in the country.

A wide range of plant-parasitic nematodes has been associated with the citrus rhizosphere but only some species cause damage to the trees (Verdejo-Lucas and McKenry, 2004). The citrus nematode (Tylenchulus semipenetrans Cobb, 1913) causes a slow decline of citrus all around the world and restricts citrus fruit production under a wide spectrum of environmental conditions (Duncan, 2005). Spreading decline is a serious disease of citrus caused by Radopholus similis (Cobb, 1893) Thorne, 1949 that only occurs in Florida's central ridge (Duncan,

\footnotetext{
1 Department of Plant Protection, College of Agriculture, Shahid Chamran University of Ahvaz, Ahvaz, Iran.

* Corresponding author: s.azimi@scu.ac.ir
}

2005). R. citri Machon and Bridge (1996) was found in citrus roots in Indonesia and was associated with very severe necrosis and root destruction (Machon and Bridge, 1996).

Pratylenchus coffeae (Zimmermann, 1898) Filipjev and Schuurmans Stekhoven, 1941, P. brachyurus (Godfrey, 1929) Filipjev and Schuurmans Stekhoven, 1941 and P. vulnus Allen and Jensen (1951) are three species of lesion nematodes associated with the citrus tree. Also, Belonolaimus longicaudatus Rau (1958) causes damage to citrus. Root-knot nematodes (Meloidogyne spp.) are able to attack citrus and are confined to prevent dissemination. Pathogenic species of root-knot nematode were reported from Taiwan and New Delhi (Duncan, 2005).

Many populations of Xiphinema brevicollum Lordello and Da Costa (1961) have been associated with the decline of grapefruit trees in Sudan (Yassin, 1974). Paratrichodorus lobatus (Colbran, 1965) has also been found in high numbers in citrus nurseries in Australia (Stirling, 1976). Hemicycliophora arenaria (Raski, 1958) is a species native to plants in the southern California that causes damage in citrus nurseries (McElroy et al., 1966). Caloosia nudata (Colbran) Brzeski, 1974 causes similar symptoms on citrus in Australia (Colbran, 1963). 
A plentiful of plant-parasitic nematode species have been associated with the citrus rhizosphere in Iran. T. semipenetrans and Diphtherophora communis (de Man, 1880) have been associated with citrus in Fars province (Abivardi et al., 1970). Meloidogyne javanica (Treub, 1885) Chitwood, 1949 from sour orange (C. aurantium) in Khuzestan province (Akhiani et al., 1984), Hemicriconemoides chiwoodi Esser (1960), Helicotylenchus pseudorobustus (Steiner, 1914) Golden, 1956, Boleodorus thylactus Thorne (1941) from orange (C. sinensis) in Kerman province (Jahanshahi afshar et al., 2006), Scutellonema brachyurus (Steiner, 1938) Andrassy, 1958 from citrus in Golestan province (Tanha Maafi et al., 2006) and Helicotylenchus macronatus Mulk and Jairajpuri (1975) have been reported from lemon (C. limon) in Kerman province (Ali Ramaji et al., 2006).

In the study by Divsalar et al. (2011), 27 species of plant-parasitic nematodes have been identified from the citrus rhizosphere in Gilan and Mazandaran as Criconemoides xenoplax Raski (1952), Filenchus facultativus (Szczygiel, 1970) Raski and Geraert (1987), Helicotylenchus exallus Sher (1966), H. vulgaris (Yuen, 1964), Ogma civellae (Steiner, 1949) Raski and Luc (1987), Paratylenchus nanus (Coob, 1923), Pratylenchus loosi (Loof, 1960), P. neglectus, P. jaehni, P. zea and Psilenchus hilarulus (de Man, 1921). Also, Hemicriconemoides chitwoodi and Tylenchorhynchus agri (Ferris, 1963) have been found associated with the rhizosphere of citrus in Kerman province (Rashidifard et al., 2014).

There is very little information about plant-parasitic nematodes associated with citrus orchards in Khuzestan province. To fill this gap, this study aimed to determine the plant parasitic nematodes of citrus in Khuzestan province, Southwestern Iran using morphological and morphometric data.

\section{Material and methods}

About 97 root and soil samples were collected from citrus orchards in the Khuzestan province, Southwestern Iran. T. semipene- trans was extracted from the roots based on the Coolen and D'Herde method (1972). Roots were washed, cut in pieces and processed for nematode extraction by blender followed by centrifugal flotation. The roots were stained (Hooper et al., 2005) and immature and mature females were observed on the root surfaces.

Soil samples were taken from 5 to $40 \mathrm{~cm}$ depth from different regions. Then the soil samples were put in a polyethylene bags with pertinent information about each sample, then brought to the laboratory and kept in the refrigerator at about $4^{\circ} \mathrm{C}$ until they were processed for nematode extraction.

The Jenkins (1964) method was used to extract the nematodes from soil samples. The collected specimens were killed in hot $4 \%$ formaldehyde solution, transferred to anhydrous glycerin according to De Grisse's (1969) method. In some samples, the tray method (Whitehead and Hemming, 1965) was employed to obtain a suspension of nematodes from the soil. Nematodes were mounted in a small drop of glycerin on permanent slides. Observations and measurements were done using an Olympus CX31 light microscope equipped with a drawing tube. Some of the best-preserved specimens were photographed using an Olympus DP12 digital camera attached to an Olympus BX51 light microscope. Nematode species were identified based on morphological and morphometric characters using valid keys such as Siddiqi 2000; Castillo and Vovlas, 2007; Geraert, 2008; Geraert, 2013.

\section{Results and discussion}

Based on morphological and morphometric characters, six species of plant-parasitic nematodes were identified, namely: Helicotylenchus abunaamai Siddiqi (1972), H. crenacauda Sher (1966), Pratylenchus allius (Shahina and Maqbool, 1996) Siddiqi (2000), P. musii Choudhury and Phukan (1989), Psilenchus hilarulus de Man (1921) and Tylenchulus semipenetrans Cobb (1913). Except T. semipenetrans, the remaining five species were found only in the rhizo- 
sphere of citrus, not in citrus roots. No further studies were performed on pathogenicity of these species on citrus plants.

Morphometric measurements of the identified nematodes closely corresponded with the published reports; nevertheless, insignificant morphological and morphometric differences were observed in some species are discussed below. The most important morphological characters of the considered species are illustrated in Figures 1-6. The morphometrics of the considered species are given in Tables 1-4.

\section{Helicotylenchus abunaamai (Siddiqi, 1972)}

Figure 1 (a-h) MEASUREMENTS (Table 1)

The general morphology of the recovered population of the species resembles the characters given in the original description (Siddiqi, 1972). However, the length of the stylet is slightly shorter (18-21.5 vs. 21-22 $\mu \mathrm{m})$. This species has been reported from Malaysia (Sauer and Winoto, 1975), Pakistan (Firoza and Maqbool, 1991), Thailand (Mizukubo et al., 1992) and Turkey (Kepenekci, 2002). There is no significant difference between our population and these populations.

Kashi and Karegar (2014) reported on the presence of the same species from sugarcane in Haft-Tappeh, Khuzestan province, Southwestern Iran. Their population has differences with the main description and our population. These differences are in body length (600-779 vs 515-611 $\mu \mathrm{m})$, ratio c (24.233.7 vs $37.6-48.2)$, ratio $c^{\prime}(1.4-1.98$ vs $1-1.2)$, length of stylet (23.3-26.8 vs 18-21.6 $\mu \mathrm{m})$ and tail length (20-29 vs 11-14 $\mu \mathrm{m})$.

In the present study, this species was recovered from $8.8 \%$ of soil samples from the rhizosphere of citrus, sour orange, lemon and tangerine in the vicinity of Dezful city, Khuzestan province, Southwestern Iran. To our knowledge, this is the first report of $H$. abunaamai in citrus orchards worldwide.

\section{Helicotylenchus crenacauda} (Sher, 1966)

Figure 1 (i-p)

\section{MEASUREMENTS (Table 1)}

The general morphology of the recovered population of the species resembles the characters given in original description (Sher, 1966). This species has been reported from the rhizosphere of rice in Gilan (Pedramfar et al., 2002 and Kashi and Karegar, 2014), ornamental plants in Mahallat (Mohammad Deimi et al., 2008) and vineyards in Markazi province, Iran (Mohammad Deimi and Mitkowski, 2010).

The population of Khuzestan province did not differ significantly from the populations of Gilan. Compared to the Mahallat population, the ratios $\mathrm{a}, \mathrm{b}^{\prime}$ and $\mathrm{c}$ are lower (25.4-29.7 vs 31.2-37.4, 4-4.9 vs 5.1-6.5 and $35-45.2$ vs $47.9-57.8$ respectively). Also, stylet length is shorter (24-25 vs 25-29 $\mu \mathrm{m})$. Compared to Markazi province, the ratio $\mathrm{c}$ is lower (35-45.2 vs 45.2-53.5).

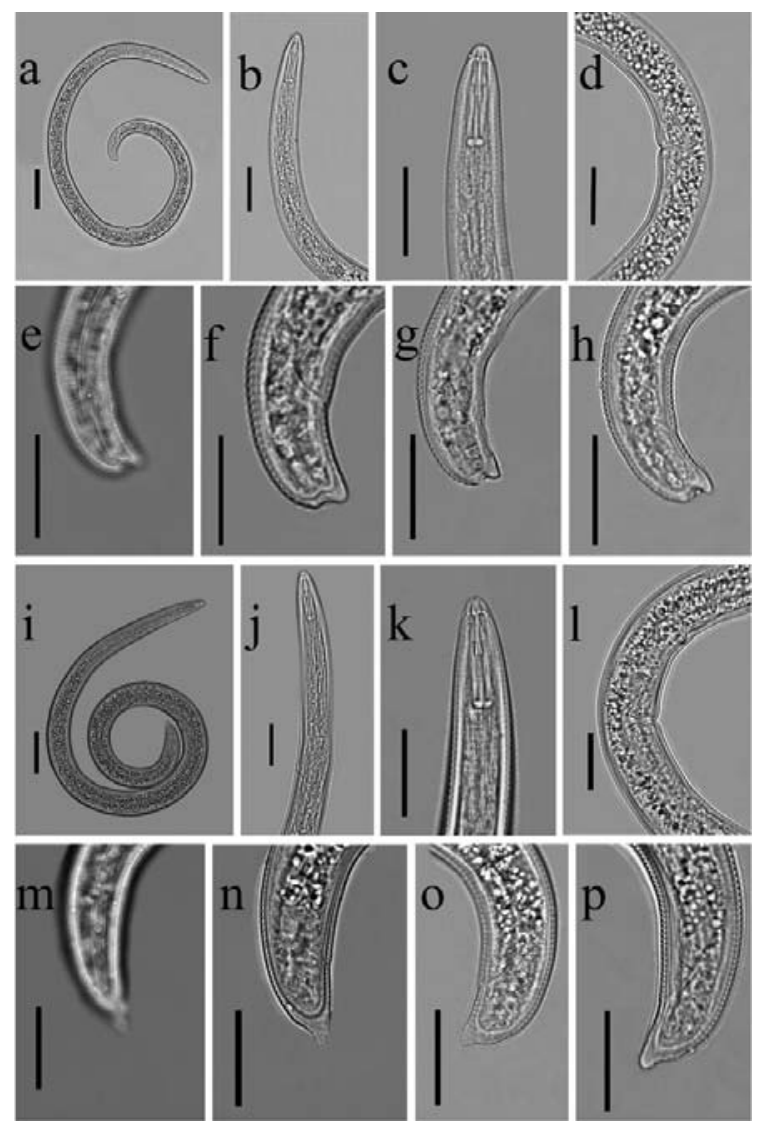

Figure 1. a-h: Helicotylenchus abunaamai. a: Entire body; b, c: Anterior region; d: Vulval region; e: Tail showing phasmid; $f-h$ : Variations of tail shape. i-p: Helicotylenchus crenacauda. i: Entire body; j, k: Anterior region; I: Vulval region; m: Tail showing phasmid; $n-p$ : Variations of tail shape. (Scale bars: $a, i=50$ $\mu \mathrm{m}, \mathrm{b}-\mathrm{h}, \mathrm{j}-\mathrm{p}=20 \mu \mathrm{m})$. 
Table 1. Morphometrics of Helicotylenchus abunaamai and Helicotylenchus crenacauda recovered from citrus orchards of Khuzestan province, southwestern Iran. All measurements are in $\mu \mathrm{m}$ and in the form: mean \pm s.d. (range).

\begin{tabular}{l|c|c}
\hline Character & Helicotylenchus abunaamai & Helicotylenchus crenacauda \\
\hline $\mathrm{n}$ & 10 & 12 \\
$\mathrm{~L}$ & $560.6 \pm 31.5(515-611)$ & $628.5 \pm 41.3(563-698)$ \\
$\mathrm{a}$ & $28.7 \pm 2.6(25.1-32)$ & $27 \pm 1.5(25.4-29.7)$ \\
$\mathrm{b}$ & $5.3 \pm 0.4(4.6-5.8)$ & $5.2 \pm 0.4(4.5-6.1)$ \\
$\mathrm{b}^{\prime}$ & $4.4 \pm 0.3(3.9-4.9)$ & $4.4 \pm 0.2(4-4.9)$ \\
$\mathrm{C}$ & $44.6 \pm 3.3(37.6-48.2)$ & $40 \pm 3.5(35-45.2)$ \\
$\mathrm{C}^{\prime}$ & $1.1 \pm 0.1(1-1.2)$ & $1.2 \pm 0.1(1-1.4)$ \\
$\mathrm{V}$ & $63.8 \pm 1.1(62.6-66.5)$ & $62.2 \pm 1(61-63.8)$ \\
Lip height & $3.7 \pm 0.4(3-4.5)$ & $3.9 \pm 0.3(3.5-4)$ \\
Lip width & $5.4 \pm 0.4(4.5-6)$ & $5.8 \pm 0.5(5-6.5)$ \\
Stylet length & $20.5 \pm 1.2(18-21.5)$ & $24.4 \pm 0.5(24-25)$ \\
Conus length & $9.8 \pm 1(8.5-11.5)$ & $11 \pm 0.7(10-12)$ \\
DGO & $9.2 \pm 0.9(8.5-10)$ & $10.2 \pm 1.2(9-12)$ \\
Pharynx length & $106.5 \pm 7.9(93.5-117)$ & $116.7 \pm 4.2(111-122.5)$ \\
Pharyngeal glands & $127.2 \pm 8.2(117-138)$ & $140.3 \pm 4.7(134-148)$ \\
Excretory pore & $90 \pm 6.3(80-102)$ & $103.5 \pm 4.4(99-112)$ \\
Median bulb & $64.7 \pm 2.8(59.5-69)$ & $74.7 \pm 2.7(72-78)$ \\
Body width & $19.5 \pm 1.3(17.5-21.5)$ & $23.2 \pm 2(19-25)$ \\
Tail length & $12.4 \pm 0.8(11-14)$ & $16 \pm 1.5(14-18)$ \\
Anal body width & $11.5 \pm 0.5(11-12)$ & $12.8 \pm 0.8(11.5-14)$ \\
Vulva body width & $19.5 \pm 1.3(17.5-21.5)$ & $23.2 \pm 2(19-25)$ \\
Vulva-Anus & $195 \pm 16.4(170-216)$ & $222.6 \pm 13.1(204-237)$ \\
Phasmids from tail terminus & $15.6 \pm 0.6(13.5-18)$ & $21 \pm 1.6(18-23)$ \\
\hline
\end{tabular}

In the present study, this species was recovered from $10.7 \%$ of soil samples from the rhizosphere of sour orange and lemon in the vicinity of Ahvaz (GPS coordinates: $31^{\circ}$ $\left.19^{\prime} 5.9^{\prime \prime} \mathrm{N} 48^{\circ} 40^{\prime} 14.2^{\prime \prime} \mathrm{E}\right)$, Dezful, Izeh (GPS coordinates: $\left.31^{\circ} 49^{\prime} 26.3^{\prime \prime} \mathrm{N}, 49^{\circ} 52^{\prime} 12.3^{\prime \prime} \mathrm{E}\right)$ and Baghmalek cities, Khuzestan province, Southwestern Iran. This is the first report of $H$. crenacauda in citrus orchards in Iran and a new record for the nematodes fauna in Khuzestan province.

\section{Pratylenchus allius}

(Shahina and Maqbool, 1996)

Siddiqi (2000)

Figures 2, 3 (a-d)

MEASUREMENTS (Table 2)

DESCRIPTION

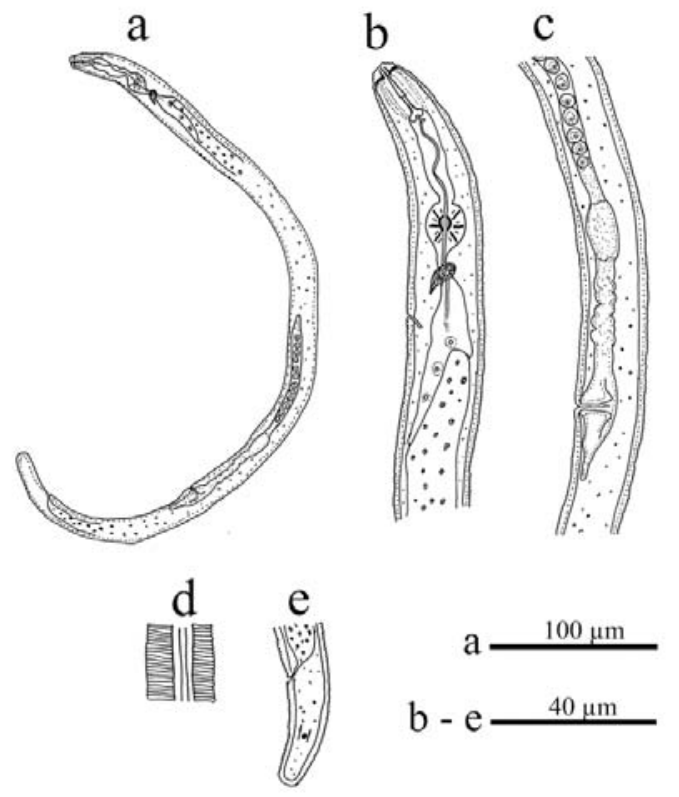

Figure 2. Female of Pratylenchus allius. a: Entire body; b: Anterior region; c: Vulval region; d: Lateral field at mid-body; e: Tail. 
Female: Nematodes are of small size (410$490 \mu \mathrm{m}$ long), with body strongly arcuate upon fixation. Cuticular annulation distinct, 0.8-1.2 $\mu \mathrm{m}$ wide at mid-body. Lateral field with four incisures, not areolated, occupying about one-third of body diameter. The labial region is low, flattened and not off set, 2.1-3.5 $\mu \mathrm{m}$ high and 6-7.2 $\mu \mathrm{m}$ wide at base, with three annuli. The framework is strongly sclerotized. The stylet is strong and relatively short, Stylet knobs well-developed, rounded, 1.8-2.4 $\mu \mathrm{m}$ high and 3-4 $\mu \mathrm{m}$ wide. The median bulb is oval in shape, very muscular, 11.8-12.6 $\mu \mathrm{m}$ long and 8.4$8.6 \mu \mathrm{m}$ wide. Nerve ring surrounds isthmus. Oesophageal glands overlap the intestine ventrally about two times the body width, three gland nuclei in tandem. Excretory pore almost at the level of the pharyngo-intestinal valve. Hemizonid is about 2-3 annuli wide, 1-3 annuli anterior to excretory pore. Genital system monodelphic-prodelphic, ovary outstretched. Anterior branch is well developed, $130-140 \mu \mathrm{m}$ long. Spermatheca oval, without sperm. Ovary with oocytes arranged in one or two rows. Vulva a transverse slit, posteriorly located, lateral flaps and epiptygma absent. The vagina is about 7-9 $\mu \mathrm{m}$ long. Post-vulval uterine sac about one-time vulval body width. Tail cylindrical, terminus rounded, without annulation. Phasmids pore-like in shape, 10-15 annuli anterior from the tail terminus.

Male: Not found. REMARKS

The Iranian population of $P$. allius is very similar to the type population of the species from Azad Kashmir, Pakistan (Shahina and Maqbool, 1996). However, the length of DGO and the number of tail annuli in our population are slightly higher than that given in the original description (0.9-1.3 vs 0.6-1 $\mu \mathrm{m}$ and $22-33$ vs $25-26$ respectively).

This species was originally described by Shahina and Maqbool (1996) as Radopholus allius. Siddiqi (2000) examined the paratype of the species and found that it belongs to the genus Pratylenchus. Castillo and Vovlas (2007) considered P. allius as a new junior synonym of $P$. thornei. Geraert
(2013) considered $P$. allius as a separate species from $P$. thornei and mentioned that the stylet is larger in P. thornei (15-19 vs 14-15.5 $\mu \mathrm{m})$. We found more differences. In $P$. allius, the length of DGO is shorter (0.6-1 vs 2-3 $\mu \mathrm{m})$, without male (vs rare male), tail tip only rounded (vs bluntly rounded or truncate) in P. thornei. We agree with Geraert's opinion and $P$. allius is considered here as separate species from $P$. thornei.

In the present study, this species was recovered from $14.7 \%$ of soil samples from the rhizosphere of orange and tangerine in the vicinity of Shush and Baghmalek cities, Khuzestan province, Southwestern Iran. This is the first record of $P$. allius for the nematode fauna in Iran.

\section{Pratylenchus musii Choudhury and Phukan (1989)}

Figures 3 (e-m), 4

MEASUREMENTS (Table 2)

DESCRIPTION

Female: Nematodes are of small size (386$450 \mu \mathrm{m}$ long), with the body slightly ventrally arcuate upon fixation. Cuticular annulation relatively fine, $0.8-1.2 \mu \mathrm{m}$ wide at mid-body. Lateral field with six incisures, not areolated, occupying about one-third

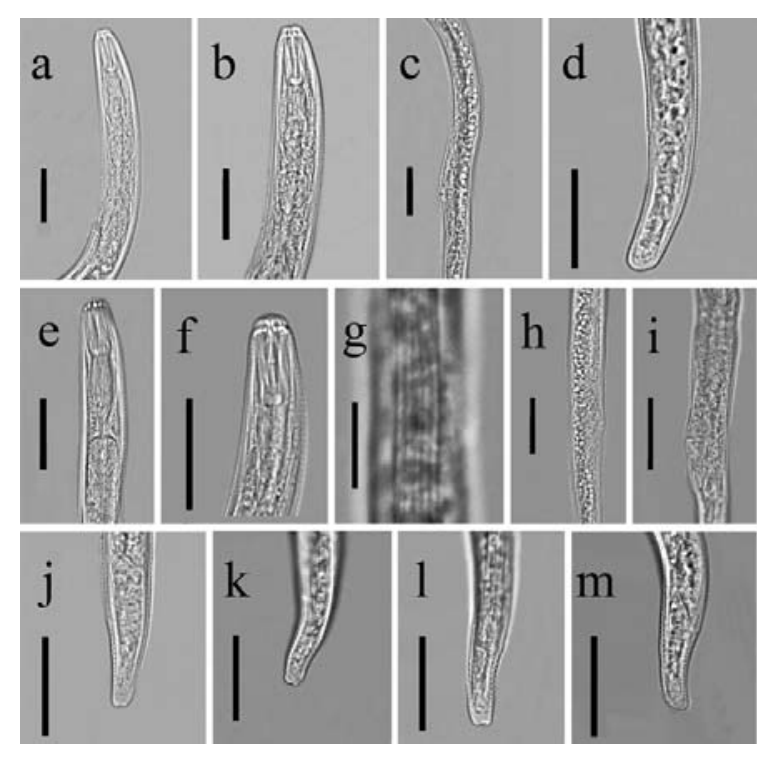

Figure 3. a-d: Female of Pratylenchus allius. a, b: Anterior region; c: Vulval region; d: Tail. e-m: Female of Pratylenchus musii. e, f: Anterior region; g: Lateral field at mid-body; $h$, i: Vulval region; j-m: Variations of tail shape. (Scale bars: $20 \mu \mathrm{m}$ ). 
Table 2. Morphometrics of Pratylenchus allius and Pratylenchus musii recovered from citrus orchards of Khuzestan province, southwestern Iran. All measurements are in $\mu \mathrm{m}$ and in the form: mean \pm s.d. (range).

\begin{tabular}{l|c|c|c|c}
\hline Character & $\begin{array}{c}\text { Pratylenchus allius } \\
\text { Khuzestan province }\end{array}$ & $\begin{array}{c}\text { Pratylenchus allius } \\
\text { (Shahina and } \\
\text { Maqbool 1996) } \\
\text { Siddiqi 2000 }\end{array}$ & $\begin{array}{c}\text { Pratylenchus mussi } \\
\text { Khuzestan province }\end{array}$ & $\begin{array}{c}\text { Pratylenchus } \\
\text { mussi } \\
\text { Geraert } \\
(2013)\end{array}$ \\
\hline $\mathrm{n}$ & 15 & 10 & 10 & - \\
$\mathrm{L}$ & $461.8 \pm 23.4(410-490)$ & $420-480.5$ & $418 \pm 21.7(386-450)$ & $430-490$ \\
$\mathrm{a}$ & $31.1 \pm 2.5(27-36.5)$ & $27.5-30$ & $27.9 \pm 2.5(25.2-32.1)$ & $30-34$ \\
$\mathrm{~b}$ & $5.8 \pm 0.8(4.4-7.2)$ & $6.4-6.7$ & $4.9 \pm 0.5(4-5.6)$ & - \\
$\mathrm{b}^{\prime}$ & $4.4 \pm 0.6(3.4-5.8)$ & $4.5-4.6$ & $3.8 \pm 0.4(3.2-4.8)$ & - \\
$\mathrm{C}$ & $20.6 \pm 2.3(17.3-25)$ & $17-20$ & $22.3 \pm 2(19.2-24.6)$ & $18-23$ \\
$\mathrm{C}^{\prime}$ & $2.3 \pm 0.5(2-2.8)$ & $2.3-2.7$ & $2.3 \pm 0.3(1.8-2.7)$ & $1.7-2.5$ \\
V & $76 \pm 1.7(73-79.2)$ & $76-77$ & $82.6 \pm 1.2(80-84.2)$ & $78-83$ \\
DGO & $1 \pm 0.1(0.9-1.3)$ & $0.6-1$ & $3.5 \pm 0.8(2.5-5)$ & $3-4$ \\
Stylet length & $14.7 \pm 0.7(14-15.5)$ & $14-15.5$ & $14.7 \pm 0.8(13.5-15.5)$ & $14-15$ \\
Stylet shaft & $7.4 \pm 0.6(6.5-8.5)$ & - & $8.2 \pm 0.5(8-9)$ & - \\
Median bulb & $46.2 \pm 4.6(41-57.5)$ & $40-43$ & $43.8 \pm 3.2(40-51)$ & - \\
Excretory pore & $65.5 \pm 6.9(50-74.5)$ & $60-68$ & $67.6 \pm 6(57-78.5)$ & $68-77$ \\
Pharynx length & $80.7 \pm 10.4(64-103)$ & $64-68$ & $83.5 \pm 6.7(75-93)$ & $98-112$ \\
Pharyngeal overlap & $104.3 \pm 11.1(84-123)$ & $99-103$ & $109.4 \pm 7(99-120)$ & - \\
head-nerve ring & $57.6 \pm 4.2(54-67)$ & - & $56.8 \pm 4.4(52-66.5)$ & - \\
Body width & $14.8 \pm 1.4(12.5-17.5)$ & 16 & $15 \pm 0.7(14-15.5)$ & 14 \\
Anal body width & $9.1 \pm 0.5(8.5-10)$ & - & $7.9 \pm 0.8(6.5-9)$ & - \\
Vulval body width & $14.6 \pm 1.3(12.5-17.5)$ & - & $12.8 \pm 0.4(12.5-14)$ & - \\
V-anus & $90.5 \pm 10(76-110.5)$ & - & $52.6 \pm 4.6(47.5-60)$ & - \\
PVUS & $14.9 \pm 1(13-17)$ & - & $14.3 \pm 1.6(14-18.5)$ & $22-30$ \\
Tail length & $22.6 \pm 2.5(19-27)$ & $24-26.4$ & $18.8 \pm 1.6(17-21.5)$ & $19-23$ \\
Lateral field width & $4.9 \pm 0.5(4-6)$ & - & $4.4 \pm 0.5(3.5-5)$ & - \\
Phasmids from tail terminus & $12.9 \pm 1.2(11-15)$ & - & $12.4 \pm 1.1(11-14.5)$ & $10-16$ \\
Num. of tail annuli & $28.8 \pm 3.2(22-33)$ & - & $20 \pm 1.7(18-23)$ & $20-26$ \\
\hline
\end{tabular}

of body diameter. The labial region is low, flattened and slightly off set, 1.6-2.3 $\mu \mathrm{m}$ high and 6-7.8 $\mu \mathrm{m}$ wide at base, with two annuli. The framework is strongly sclerotized. The stylet is strong and relatively short, Stylet knobs well-developed, rounded, 1.8$2.4 \mu \mathrm{m}$ high and 3.6-4.5 $\mu \mathrm{m}$ wide. The median bulb is oval in shape, 10.8-12 $\mu \mathrm{m}$ long and 9.6-11.4 $\mu \mathrm{m}$ wide, 40-51 $\mu \mathrm{m}$ from anterior end. Nerve ring surrounds isthmus. Oesophageal glands overlap the intestine ventrally about two times the body width, three gland nuclei almost in tandem. Excretory pore slightly higher than the pharyngo-in- testinal valve. Hemizonid is about two annuli wide, 1-3 annuli anterior to excretory pore. Genital system monodelphic-prodelphic, ovary outstretched. Anterior branch is well developed, 132-143 $\mu \mathrm{m}$ long. Spermatheca is oval in shape, with sperm. Ovary with oocytes arranged in one or two rows. Vulva a transverse slit, posteriorly located, lateral flaps and epiptygma absent. The vagina is about 6.5-8 $\mu \mathrm{m}$ long. Post-vulval uterine sac more than one-time vulval body width. Tail cylindrical, terminus rounded, with annulation. Phasmids pore-like in shape, 11-15 annuli anterior from the tail terminus. 
Male: Not found.

\section{REMARKS}

According to the morphological characters and morphometric data given in Geraert (2013), there were no differences between the Iranian population of $P$. musii and the original description. However, the postuterine sac length is shorter (14-18.5 vs 22$30 \mu \mathrm{m})$.

The species was originally recovered from the rhizosphere of banana and described by Choudhury and Phukan, 1989 from Assam, India (Geraert, 2013). In a study of nematode community associated with banana in Assam, India, Deori et al., 2014 found that $P$. musii was one of the predominant nematode species around the banana rhizosphere.

In the present study, this species was recovered from $9.8 \%$ of soil samples from the rhizosphere of orange and tangerine in the vicinity of Shush city, Khuzestan province, Southwestern Iran. This is the first record of $P$. musii for the nematode fauna in Iran.

\section{Psilenchus hilarulus de Man (1921)}

\section{Figure 5}

\section{MEASUREMENTS (Table 3)}

Iranian population of $P$. hilarulus is in morphological and morphometric agreement with the original description (Geraert, 2008). However, the length of female body is shorter $(640-845$ vs $890-1150 \mu \mathrm{m})$. This species has been reported from the citrus rhizosphere in Mazandaran province, Iran (Divsalar et al., 2011). Also, has been reported from the rhizosphere of sugarcane in Khuzestan province, Iran (Kheiri, 1995). In the present study, this species was recovered from $20.5 \%$ of soil samples from the rhizosphere of orange, lemon and sour orange in the vicinity of Shush, Dezful, Ramhormoz, Baghmalek and Ramin cities, Khuzestan province, Southwestern Iran.

\section{Tylenchulus semipenetrans Cobb (1913)}

Figure 6

MEASUREMENTS (Table 4)

Characters measured in Khuzestan population of $T$. semipenetrans are consistent

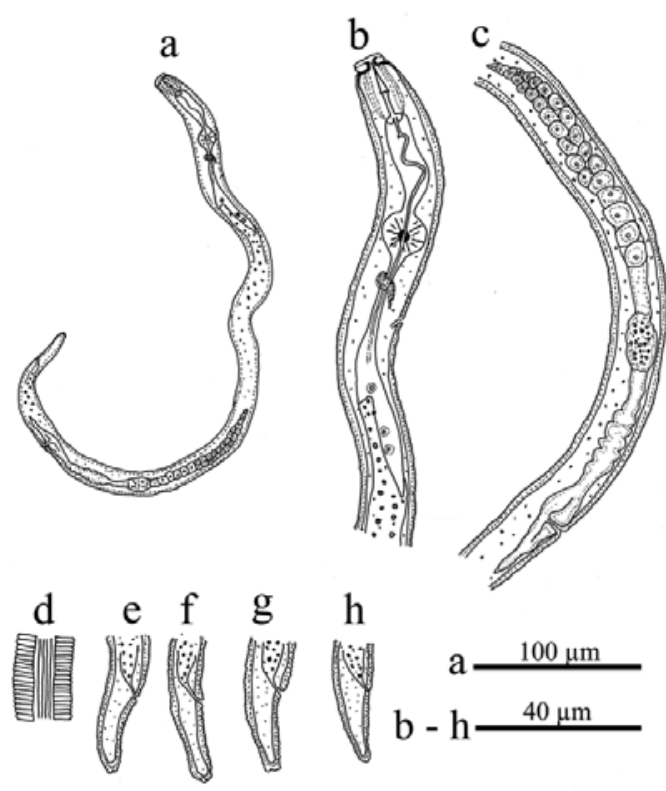

Figure 4. Female of Pratylenchus musii. a: Entire body; b: Anterior region; c: Vulval region; d: Lateral field at mid-body; e-h: Tail.

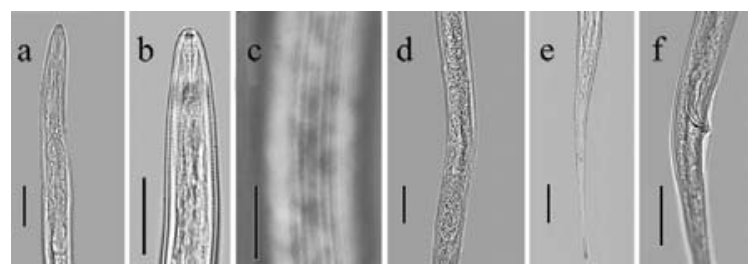

Figure 5. Psilenchus hilarulus. a, b: Anterior region; c: Lateral field at mid-body; d: Vulval region; e: Female tail; f: Male tail. (Scale bars: $20 \mu \mathrm{m})$.

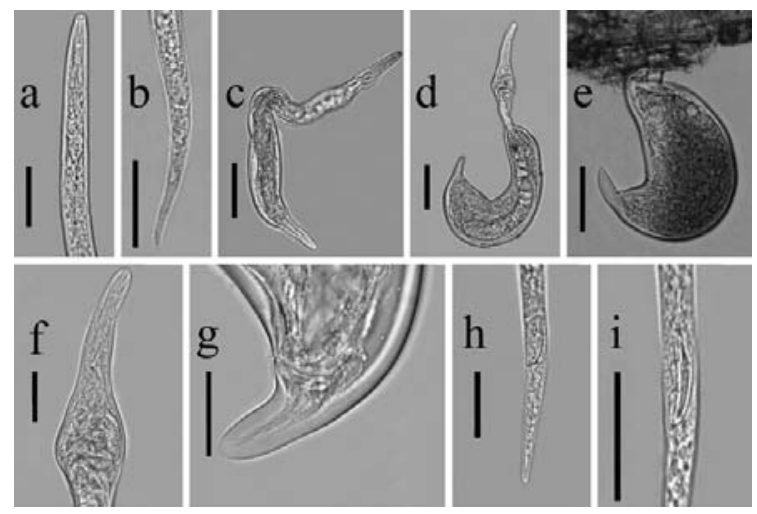

Figure 6. Tylenchulus semipenetrans. a: Anterior region of Juvenile; $b$ : Posterior region of Juvenile; $c$ Immature female; $d$, e: Mature female; f: Anterior region of female; g: Posterior region of female; $h$, i: Male tail. (Scale bars: $a, b=20 \mu \mathrm{m}$, c-e $=$ $50 \mu \mathrm{m}, \mathrm{f}-\mathrm{i}=20 \mu \mathrm{m})$. 
Table 3. Morphometrics of Psilenchus hilarulus recovered from citrus orchards of Khuzestan province, southwestern Iran. All measurements are in $\mu \mathrm{m}$ and in the form: mean \pm s.d. (range).

\begin{tabular}{l|c|c}
\hline Character & \multicolumn{2}{|c}{ Psilenchus hilarulus } \\
\hline & Female & Male \\
\hline $\mathrm{n}$ & 11 & 12 \\
$\mathrm{~L}$ & $760 \pm 82(640-845)$ & $737.4 \pm 78.3(643-841)$ \\
$\mathrm{a}$ & $46.5 \pm 2.1(43.3-48.9)$ & $45.3 \pm 5(36.7-52.9)$ \\
$\mathrm{b}$ & $6 \pm 0.6(5-6.7)$ & $5.9 \pm 0.7(4.8-6.8)$ \\
$\mathrm{C}$ & $7 \pm 0.5(6-7.6)$ & $6.1 \pm 0.4(5.6-6.7)$ \\
$\mathrm{C}^{\prime}$ & $10.1 \pm 0.9(8.6-11.6)$ & $10.1 \pm 1(8.5-12.2)$ \\
$\mathrm{V}$ & $48.8 \pm 1.9(44.5-51.3)$ & - \\
$\mathrm{V}^{\prime}$ & $57.1 \pm 1.8(54.7-59.3)$ & - \\
Stylet length & $13.3 \pm 0.7(12-14.5)$ & $13.1 \pm 0.3(12.5-14)$ \\
$\mathrm{m}$ & $35.9 \pm 5(28.5-45.5)$ & $36.9 \pm 3.3(32-43)$ \\
DGO & $4.5 \pm 0.8(3.5-6)$ & $4.3 \pm 0.7(3.5-6)$ \\
Oesophagus & $129 \pm 4.9(125-140)$ & $125 \pm 8(108.5-140)$ \\
MB & $54.7 \pm 1.5(52-57.5)$ & $54.7 \pm 1.9(52-59)$ \\
Body width & $16.8 \pm 1.7(14-19)$ & $16.4 \pm 1.9(13-18.5)$ \\
Excretory pore & $93.4 \pm 5.9(84-105)$ & $92 \pm 7.1(86-105.5)$ \\
Vulval body width & $14.8 \pm 1.3(13.5-16)$ & - \\
Vulva-anus & $285.8 \pm 40(218-345)$ & - \\
Anal body width & $10.2 \pm 0.7(9.5-11)$ & $11.3 \pm 0.9(11-12.5)$ \\
Tail length & $117 \pm 8.5(108-138)$ & $120 \pm 7.6(112-132)$ \\
T/VA & $0.4 \pm 0(0.34-0.48)$ & - \\
Spicule length & - & $22.1 \pm 2.1(20-24.5)$ \\
Gubernaculum length & - & $4.5 \pm 0.6(6.5-8.5)$ \\
Bursa & - &
\end{tabular}

with other populations including Inserra et al. (1988) and Rashidifard et al. (2015). However, the length of the stylet in second stage juveniles $(\mathrm{J} 2)$ is slightly shorter (9.5-12.5 vs 12.2-13.2 $\mu \mathrm{m})$.

T. semipenetrans has been reported from the roots of various plants like citrus (Fars, Mazandaran, Golestan, Lorestan, Khuzestan, Kerman, Boushehr and Hormozgan provinces), olive (Kermanshah and Mazandaran provinces) and grape (Mazandaran and Markazi provinces) in Iran (Ghaderi et al.,
2012). Also, has been reported from the root samples of pomegranate in Kerman province (Rashidifard et al., 2015). In the present study, this species was recovered from $19.9 \%$ of root samples from the rhizosphere of orange, sour orange, lemon and tangerine in the vicinity of Ahvaz, Abadan, Ramin, Shush, Dezful, Baghmalek, Andimeshk, Behbahan cities, Khuzestan province, Southwestern Iran. 
Table 4. Morphometrics of Tylenchulus semipenetrans recovered from citrus orchards of Khuzestan province, southwestern Iran. All measurements are in $\mu \mathrm{m}$ and in the form: mean \pm s.d. (range).

\begin{tabular}{|c|c|c|c|}
\hline \multirow[t]{2}{*}{ Character } & \multicolumn{3}{|c|}{ Tylenchulus semipenetrans } \\
\hline & Female & $J 2$ & Male \\
\hline $\mathrm{n}$ & 8 & 8 & 6 \\
\hline L & $328 \pm 30.8(288-366)$ & $320 \pm 22.1(297-364)$ & $309.5 \pm 23(286-334)$ \\
\hline a & $6.6 \pm 1.3(4.5-7.9)$ & $28 \pm 2.8(24-32)$ & $34.1 \pm 1.9(32-36.7)$ \\
\hline b & - & $3.4 \pm 0.1(3.2-3.5)$ & $5 \pm 0.6(4-5.5)$ \\
\hline St & $10.5 \pm 1.2(9.5-12.5)$ & $11 \pm 0.8(9.5-12.5)$ & $8.5 \pm 0.8(8-9.5)$ \\
\hline DGO & $6 \pm 1.9(4-8)$ & - & - \\
\hline Median bulb & $60 \pm 5(52-64)$ & $46.5 \pm 2.3(42-49)$ & $40 \pm 2.4(36-41.5)$ \\
\hline Median bulb length & $16 \pm 3(14-19)$ & - & - \\
\hline Median bulb width & $14.5 \pm 0.3(13-15)$ & - & - \\
\hline Pharynx length & $103 \pm 17.9(84-132)$ & $94 \pm 5.3(84-104)$ & $58 \pm 4.5(51-63.5)$ \\
\hline Basal bulb length & $18.5 \pm 0.8(16-20.5)$ & - & - \\
\hline Basal bulb width & $13.5 \pm 1.9(11-16)$ & - & - \\
\hline Ex. pore from anterior end & $285 \pm 31.9(231-314.5)$ & $177.5 \pm 13(156.5-192)$ & - \\
\hline Ex. pore/L \% & $85 \pm 2.9(80.9-88.4)$ & $54.9 \pm 2.5(52.5-59.4)$ & - \\
\hline Vulva-excretory pore distance & $16.5 \pm 1.9(13-18)$ & - & - \\
\hline Post-vulva section width (PVSW) & $16 \pm 1.8(14.5-18)$ & - & - \\
\hline Post-vulva section length (PVSL) & $25 \pm 4.2(19-28)$ & - & - \\
\hline Swollen posterior body length & $196 \pm 32(150-237)$ & - & - \\
\hline $\begin{array}{l}\text { Swollen posterior body as \% of } \\
\text { total body length }\end{array}$ & $58.9 \pm 9.2(43-64.7)$ & - & - \\
\hline Cuticle thickness at mid-body & $5 \pm 1.3(3-6.5)$ & - & - \\
\hline Neck length & $3.5 \pm 9.8(30-52)$ & - & - \\
\hline Vulval body width & $33 \pm 7.7(24-44)$ & - & - \\
\hline Anterior end to nerve ring & - & $61.5 \pm 2.4(57-63.5)$ & - \\
\hline $\begin{array}{l}\text { Excretory pore genital Primordi- } \\
\text { um distance }\end{array}$ & - & $25.5 \pm 3.1(22-29.5)$ & - \\
\hline $\begin{array}{l}\text { Anterior end to genital Primor- } \\
\text { dium }\end{array}$ & - & $205 \pm 18.2(183.5-230)$ & - \\
\hline $\begin{array}{l}\text { Genital primordium to Posteri- } \\
\text { or end }\end{array}$ & - & $115 \pm 12.2(93-135)$ & - \\
\hline Genital primordium (\%) & - & $64 \pm 3.2(61.2-71.1)$ & - \\
\hline Body width at mid-body & $50.5 \pm 10.7(37-64)$ & $12.5 \pm 0.6(12-13)$ & $9 \pm 0.9(8-10)$ \\
\hline Anal body width & - & - & $7 \pm 0.7(6-8)$ \\
\hline Spicules & - & - & $18.5 \pm 1.5(16-20)$ \\
\hline Gubernaculum & - & - & $4.5 \pm 0.6(4-5.5)$ \\
\hline Tail & - & - & $33.5 \pm 3.7(28.5-38)$ \\
\hline
\end{tabular}


The authors are grateful to Shahid Chamran University of Ahvaz for financial support.

\section{Literature cited}

Abivardi, C., Izadpanah, K. and Saffarian, A. 1970. Plant-parasitic nematodes associated with citrus decline in southern Iran. Plant Disease Reporter, 54: 339-342.

Akhiani, A., Mojtahedi, H. and Naderi, A. 1984. Species and physiological races of root- knot nematodes in Iran. Iranian journal of plant pathology, 20: $57-70$.

Ali Ramaji, F., Pourjam, E. and Karegar, A. 2006. Species of Helicotylenchus steiner 1954 from Jiroft and Kahnoj region. Iranian Journal of plant pathology, 42: 473- 489.

Castillo, P. and Vovlas, N. 2007. Pratylenchus (Nematoda: Pratylenchidae): diagnosis, biology, pathogenicity and management. Hunt, D.J. and Perry, R.N. (eds). Nematology monographs and Perspectives, volume 6. Leiden, The Netherlands, Brill Academic Publishers, $530 \mathrm{p}$.

Colbran, R.C. 1963. Studies of plant and soil nematodes. 6. Two new species from citrus orchards. Queensland Journal of Agricultural Science, 20: 469-474.

Coolen, W.A. and D'Herde, C.J. 1972. A method for the quantitative extraction of nematodes from plant tissue. State Agricultural Entomology Research Station. Ghent, Belgium, $77 \mathrm{p}$.

De Grisse, A.T. 1969. Redescription and modification of some techniques used in the study of nematodes phytoparasitaires. Mededelingen Rijksfacultiet Landbouw Wetenschappe Gent, 34: 351-369.

Deori, A., Das, D. and Sumita, K. 2014. Nematode community around banana rhizosphere in Jorhat district of Assam. Indian Journal of Nematology, 44: 252-254.

Divsalar, N., Jamali, S., Pedramfar, H. and Taheri, H. 2011. Identification of plant parasitic nematodes of citrus orchards in Guilan east and Mazandaran west province. Journal of Plant Protection, 25: 168-177.

Duarte, A., Fernandes, J., Bernardes, J. and Miguel, J. 2016. Citrus as a component of the Mediterranean diet. Journal of Spatial and Organizational Dynamics, 6: 289-304.

Duncan, L.W. 2005. Nematode parasites of citrus. In Luc, M., Sikora, R.A. and Bridge, J. (eds). Plant parasitic nematodes in subtropical and tropical agriculture. Wallingford: $C A B$ International, p. 437-466.

FAOSTAT. 2017. Citrus Fruit-Fresh and Processed. Food and Agriculture Organization of the United Nations. Available at: http://faostat.fao.org

Firoza, K. and Maqbool, M.A. 1991. Description of
Rotylenchus capsicum n. sp. and morphometric data on five known species of the genus Helicotylenchus Steiner, 1945 (Nematoda: Hoplolaimidae) recorded from Pakistan. Pakistan Journal of Nematology, 9: 71-78.

Geraert, E. 2008. The Tylenchidae of the world: Identification of the family Tylenchidae (Nematoda: Tylenchida). Ghent, Belgium, Academia Press, $530 \mathrm{p}$.

Geraert, E. 2013. The Pratylenchidae of the world: Identification of the family Pratylenchidae (Nematoda). Ghent, Belgium, Academia Press, 430 p.

Ghaderi, R., Kashi, L. and Karegar, A. 2012. The nematodes of Iran, based on the published reports until 2011. Agricultural Education and Extension Publication: Tehran, Iran, 371 p.

Hooper, D.J., Hallmann, J. and Subbotin, S.A. 2005. Methods for extraction, processing and detection of plant and soil nematodes. In Luc, M., Sikora, R.A. and Bridge, J. (eds). Plant parasitic nematodes in subtropical and tropical agriculture. Wallingford: CAB International, p. 53-86.

Inserra, R.N., Vovlas, N., O'bannon, J.H. and Esser, R.P. 1988. Tylenchulus graminis n. sp. and T. palustris n. sp. (Tylenchulidae), from native flora of Florida, with notes on $T$. semipenetrans and $T$. furcus. Journal of Nematology, 20: 266-287.

Jahanshahi Afshar, F., Pourjam, E. and Kheiri, A. 2006. Tylenchs associated with jiroft orchards and a description of four newly found species for the nematode fauna of Iran. Iranian Journal of Agricultural Sciences, 37: 529-545.

Jenkins, W.R. 1964. A rapid centrifugal flotation technique for separating nematodes from soil. Plant Disease Reporter, 48: 692.

Kashi, L., Karegar, A. 2014. Description of Helicotylenchus persiaensis sp. n. (Nematoda: Hoplolaimidae) from Iran. Zootaxa, 3785: 575-588. DOI: 10.11646/zootaxa.3785.4.6.

Kepenekci, İ. 2002. Plant parasitic nematode species of Tylenchida (Nematoda) associated with sesame (Sesamum indicum L.) growing in the Mediterranean region of Turkey. Turkish Journal of Agriculture and Forestry, 26: 323-330.

Kheiri, A. 1995. Plant parasitic nematode fauna of sugarcane in Iran. Nematologica, 41: 277-356.

Machon, J.E. and Bridge, J. 1996. Radopholus citri n.sp. (Tylenchida: Pratylenchidae) and its pathogenicity on citrus. Fundamental and Applied Nematology, 19: 127-133.

McElroy, F.D., Sher, S.A. and Van Gundy, S.D. 1966. The sheath nematode Hemicycliophora arenaria, a native to California soils. Plant Disease Reporter, 40: 581-583.

Mizukubo, T., Toida, Y. and Keereewan, S. 1992. A survey of nematodes attacking crops in Thailand. I. Genus Helicotylenchus Steiner, 1945. Japanese Journal of Nematology, 22: 26-36.

Mohammad Deimi, A., Chitambar, J.J. and Tanha 
Maafi, Z. 2008. Nematodes associated with flowering ornamental plants in Mahallat, Iran. Nematologia Mediterranea, 36: 115-123.

Mohammad Deimi, A. and Mitkowski, N. 2010. Nematodes associated with vineyards throughout Markazi province (Arak), Iran. Australasian Plant Pathology, 39: 571-577. doi: 10.1071/AP10044.

Pedramfar, H., Pourjam, E. and Kheiri, A. 2002. Plant parasitic nematodes associated with rice in $\mathrm{Gi}$ Ian Province. Iranian Journal Plant Pathology, 37: 285-301.

Rashidifard, M., Shokoohi, E., Hoseinipour, A. and Jamali, S. 2014. Study of nematodes in the rhizosphere of citrus orchards southeast of Iran. Journal of Nematology, 46: 226.

Rashidifard, M., Shokoohi, E., Hoseinipour, A. and Jamali, S. 2015. Tylenchulus semipenetrans (Nematoda: Tylenchulidae) on pomegranate in Iran. Australasian Plant Disease Notes, 10: 1-6. DOI: 10. 1007/s13314-014-0157-7.

Sauer, M.R. and Winoto, R. 1975. The genus Helicotylenchus Steiner, 1945 in West Malaysia. Nematologica, 21: 341-350.

Shahina, F. and Maqbool, M.A. 1996. Two new species of the genus Radopholus Thorne, 1949 (Nematoda: Pratylenchidae) from Pakistan. Fundamental and Applied Nematology, 19: 289-292.

Sher, S.A. 1966. Revision of the Hoplolaiminae (Nematoda). VI. Helicotylenchus Steiner, 1945. Nematologica, 12: 1-56. DOI: 10.1163/187529266x00013.
Siddiqi, M.R. 1972. On the genus Helicotylenchus Steiner, 1945 (Nematoda: Tylenchida), with descriptions of nine new species. Nematologica, 18: 74-91. DOI: 10.1163/187529272x00278.

Siddiqi, M.R. 2000. Tylenchida: parasites of plants and insects. CABI Publishing, Wallingford, UK, $848 \mathrm{p}$.

Stirling, G.R. 1976. Paratrichodorus lobatus associated with citrus, peach and apricot trees in South Australia. Nematologica, 22: 138-144. DOI: 10.1163/187529276X00210.

Tanha Maafi, Z., Ebrahimi, N., Barooti, S., Khozeini, F. and Karegar, A. 2006. Occurrence of Scutellonema brachyurus (Stiener, 1938) Andrassy, 1956 in Damghan, Guilan and Gollestan region. Iranian journal of Plant Pathology, 42: 197-200.

Verdejo-Lucas, S. and McKenry, M.V. 2004. Management of the Citrus Nematode, Tylenchulus semipenetrans. Journal of Nematology, 36: 424-432.

Whitehead, A.G. and Hemming, J.R. 1965. A comparison of some quantitative methods of extracting small vermiform nematodes from soil. Annual Applied Biology, 55: 25-38.

Yassin, A.M. 1974. A note on Longidorus and Xiphinema species from the Sudan. Nematologia Mediterranea, 2: 141-147.

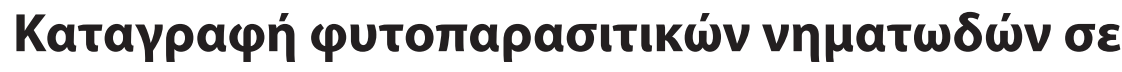

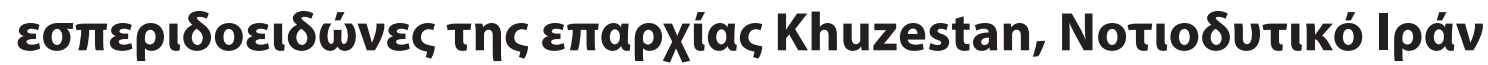

\author{
P. Eisvand, R. Farrokhi Nejad kaı S. Azimi
}

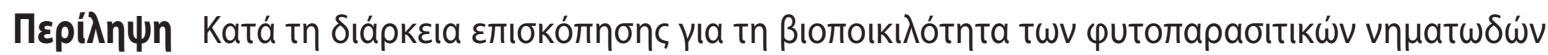

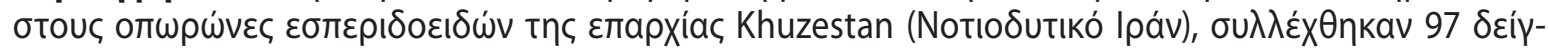

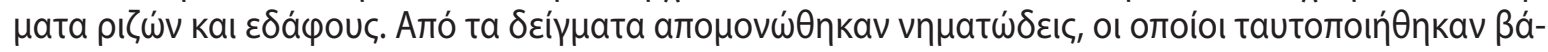

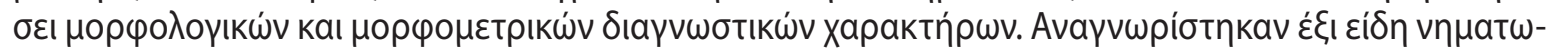

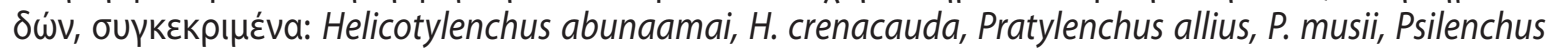

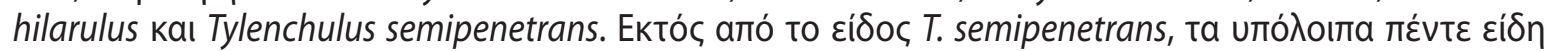

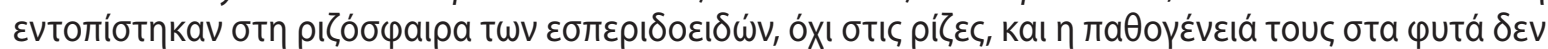

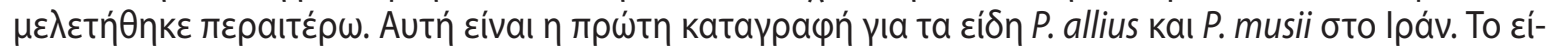

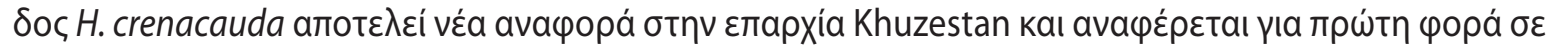

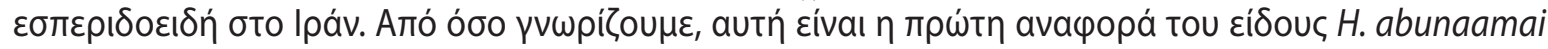

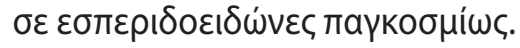

Hellenic Plant Protection Journal 12: 97-107, 2019 